\title{
Acculturation and Its Discontents: A Case for Bringing Anthropology Back into the Conversation
}

\author{
Peter J. Guarnaccia ${ }^{1, *}$, Carolina Hausmann-Stabile ${ }^{2}$ \\ ${ }^{1}$ Institute for Health, Health Care Policy \& Aging Research, Rutgers University, USA \\ ${ }^{2}$ School of Social Work, College of Public Health, Temple University, USA
}

Copyright $\mathrm{O} 2016$ by authors, all rights reserved. Authors agree that this article remains permanently open access under the terms of the Creative Commons Attribution License 4.0 International License

\begin{abstract}
Anthropologists' contribution to the study of cultural change is urgent in light of the increasing number of people of different backgrounds who are migrating around the globe and settling in new communities, and the opportunities and challenges that come along with that process. By examining the anthropological literature on acculturation going back to the 1936 Memorandum by Redfield, Linton and Herskovits, this paper reviews and assesses the discipline's perspective on acculturation, and lays out the case for why it is critical for anthropologists to re-engage the concept. Although other disciplines, particularly psychology and sociology, have dominated the field of acculturation research more recently, they mostly have done so with a narrow focus. While it is important to acknowledge the pitfalls of anthropology's past study of acculturation, there are important features of the acculturation construct that continue to be relevant. Among these are the study of acculturation as a process that is multidimensional; the investigation of how different kinds of power affect the acculturation process; the impacts of attitudes, actions and policies of the receiving group on how acculturation proceeds; the role of "real history" in understanding processes of acculturation; and the global perspective on these processes. We suggest ways in which anthropologists can reignite the field of acculturation research by engaging with Redfield, Linton and Herskovits' framework and subsequent anthropological literature.
\end{abstract}

Keywords Acculturation, Anthropology, Real History, Power

\section{Introduction}

In 1936, Robert Redfield, Ralph Linton and Melville Herskovits published a "Memorandum for the Study of Acculturation" in the American Anthropologist [1]. The Memorandum, funded by the Social Science Research Council, put forth a coherent framework for social science research on acculturation. Even though at the time of its publication, the Memorandum's proposed framework was in skeletal form, it provided a broad blueprint for the key research that is still relevant to this day. For the next 40 years there was a flourishing of anthropological research on acculturation, which included an updated formulation of the Memorandum's research program, organized by the Social Science Research Council Summer Seminar on Acculturation and published in the American Anthropologist in 1954 [2]. And then acculturation largely disappeared from the anthropological literature [3, 4]. The disappearance of acculturation scholarship was in part due to anthropologists' increasing questioning of the "culture concept" and the post-modern turn in the field. It was also due to the applied nature of the term and its negative association with colonial projects, especially British Anthropology in Africa and American Anthropology among American Indians [3, 4]. By the early 1990s, the focus on globalization and transnationalism supplanted anthropologists' use of the acculturation frame for the study of immigrants [5], and the concepts of hybridity, bricolage and creolization supplanted the use of acculturation for studying how cultures combine into new cultural formations [see for example, 6].

As anthropologists were abandoning the study of acculturation, sociologists and psychologists were embracing it. Both disciplines, however, approached the study of acculturation from their own epistemological and methodological perspectives and only marginally recognized the contributions of anthropology. For the most part, sociology focused on the assimilation of ethnic groups in the U.S., both in the largely European immigration of the early $20^{\text {th }}$ Century and the later $20^{\text {th }}$ and $21^{\text {st }}$ Century waves of immigrants from Latin America, Asian and Africa [7]. Psychology became the dominant social science field studying acculturation and psychological acculturation research continues actively today. Psychologists focused on the traits of acculturation and their measurement. Consequently, psychologists created many cross-sectional measures that reduced the phenomenon to a series of Likert scales about language proficiency, food, media and music. 
Influenced by the sociological research on assimilation, the initial acculturation scales developed by psychologists assumed a one-dimensional movement from the culture of origin to the host culture, most focused on the U.S. and on Latino immigrants. Later versions followed a shift in acculturation theory that moved away from a focus on assimilation to an interest in biculturalism based on John Berry's work [8]. These acculturation scales aimed at assessing the simultaneous and distinct involvement in the culture of origin and the host culture, and positioned individuals within a four-fold model of acculturation outcomes: integration, separation, assimilation and marginalization.

While many of the articles in psychology and sociology cited the 1936 definition of acculturation, they never really engaged the program of research outlined in the Memorandum and rarely acknowledged the extensive body of anthropological research that followed. Beyond citing the early definition, it appeared that anthropology had disappeared from contemporary discussions of acculturation. We would argue that a rich set of approaches and insights into acculturation processes was lost and that the field of acculturation studies suffered from the narrowing of perspective reflected in much of the work in sociology and especially psychology.

Why would we argue that anthropology should re-engage with acculturation research at this juncture? We feel strongly that anthropology needs to recapture the concept of acculturation both for itself and for the broader social sciences and to develop the concept and its implications further. Many may argue, as Hunt and colleagues [9] did in their paper on acculturation in health research, that acculturation has lost its usefulness because of its imprecise and often stereotypical usage. Yet as we survey the contemporary scene, acculturation issues surround us and call for our urgent scientific engagement. For example, debates in the U.S. about the "new immigration" and Latinoization of the U.S. are issues that acculturation approaches could contribute to understanding. Debates about immigration reform in the U.S. reflect issues of acculturation. A reinvigorated program of acculturation research could reposition anthropology centrally in discussion of ethnic relations in the U.S. and globally.

What are the strengths that anthropologists bring to the study of acculturation? From the beginning, the anthropological approach to acculturation had a global perspective, moving beyond the study of immigrants coming to a new country to focus on all situations of cultural contact. Anthropologists understood that the meeting of cultural groups did not happen in a vacuum, and that the historical diversity across groups shaped the acculturation processes. In line with Herskovits' [10, 11] suggestions, anthropologists emphasized the role of context and "real history" in understanding processes of acculturation. Furthermore, anthropological formulations of acculturation have always highlighted the importance of how different kinds of power affect acculturation processes. This is why an anthropological program of acculturation research includes not only studying the groups that are undergoing acculturation, but also looking at the process in relation to the impacts of the attitudes, actions and policies of the broader society on how acculturation proceeds. In addition, anthropology has always viewed acculturation as a complex process that is multidirectional and can lead to a wide range of possible outcomes. Had other fields absorbed these fundamental insights, it could have saved a lot of years of less than productive research.

In this paper, we will make the case for why a re-invigorated focus on acculturation is in the interests of anthropology as a field and as an applied discipline that can contribute to the understanding of processes of culture contact, immigration and the status of diverse individuals and groups in a range of contexts. We present a selective review of the anthropological literature to highlight the key dimensions of an anthropological approach to acculturation that would form the core of such an endeavor. We also discuss current developments in sociology and psychology that resonate with this critical discussion. We highlight the promising direction of a phenomenological turn in acculturation research. Finally, we suggest how a robust anthropological program on acculturation can help to reinvigorate the field.

\section{Memorandum for the Study of Acculturation}
"Acculturation comprehends those phenomena which result when groups of individuals having different cultures come into continuous first-hand contact, with subsequent changes in the original cultural patterns of either or both groups" [1:149].

By the time the "Memorandum for the Study of Acculturation" (the Memo) was written, there were already multiple and conflicting definitions of acculturation. This prompted The Social Science Research Council to commission Robert Redfield, Ralph Linton, and Melville Herskovits in 1936 to " ... analyze the work on the problem already done, to study the implications of the term 'acculturation,' and to explore new leads for further investigation" [1:149]. Written by three of the giants of anthropology of their time, the Memo was intended as both an assessment of previous research and template for where the study of acculturation should go. Besides providing a definition of acculturation, the Memo provided a basic roadmap of elements to consider in the analysis of the processes and outcomes of acculturation research. As time went by, the Memo became the conceptual statement of acculturation for the social sciences and its longevity is attested to by how widely it is still cited in papers from fields beyond anthropology. However, scholars and researchers used the Memo in a limited way, often only referring to its definition of acculturation and leaving its fundamental 
conceptual and methodological suggestions unexamined. This is unfortunate, for while the definition now appears vague and somewhat poorly written, the substance of the Memo provides an excellent blueprint for research on acculturation. We argue that had the Memo's framework been taken seriously, the broader study of acculturation would have avoided many of the conceptual and methodological pitfalls that plague it today.

The Memo starts by suggesting that acculturation processes have characterized group contacts from the earliest periods of human history, making it clear that this is neither a new nor a unique phenomenon to the $20^{\text {th }}$ and $21^{\text {st }}$ centuries. Redfield, Linton, and Herskovits continue by making important distinctions between acculturation, culture-change, assimilation, and diffusion. For them, cultural change is a broader term encompassing, but not limited to, acculturation. Assimilation, which they identify as a potential phase of the acculturation process, involves one culture adopting cultural features of another. Lastly, diffusion refers to a dissemination of cultural elements that is present in-but not exclusive to-acculturation processes. The authors place considerable emphasis on the fact that cultural contact must be first hand and prolonged among groups, and argue that acculturation does not occur from casual contact. While they emphasize first-hand or face-to-face contact as needed for acculturation processes, it is unlikely that the authors could have anticipated in 1936 the global flows of media and other cultural interchanges that now characterize the late $20^{\text {th }}$ and $21^{\text {st }}$ centuries [for an excellent example of the role of media in changing gender identity and body image, see 12].

Redfield, Linton, and Herskovits were interested in the bidirectional movement of cultural features among cultural groups, so that in the end, each group was often changed through acculturation processes. The authors suggested critical dimensions to analyzing these processes, including understanding the differences in the types, situations, and processes of cultural contact. Regarding the types of cultural contacts, Redfield, Linton, and Herskovits called for a nuanced understanding of the nature of the groups that came into contact with each other. As part of this process, they suggested avoiding the use of broad cultural labels to describe the groups in contact, and recommended that researchers identify whether the groups entering in contact represent whole groups or selected members of a community, such as the case of missionaries or immigrant males.

The next focus of analysis in the Memo were the situations of contact; which referred to exploring how diverse cultural groups came into contact with each other. One important dimension of study was whether the cultural elements were taken on voluntarily or forced on one group by the other. Another was the degree of social inequality between the groups leading to important power differentials. These power differentials could be accentuated by political or social dominance of one group by another. Although critical, this analysis of the dimensions of power in the acculturation relationship and process is missing from many later formulations right up to the present time. While sociologists recognize the role of state institutions, such as schools, in promoting the assimilation process, psychologists often treat acculturation as a series of individual voluntary choices between the culture of origin and the new culture [13].

Since acculturation involves cultural interchange, the Memo focused on delineating the specific details of which traits moved among and were adopted by the groups in contact. This process has important dimensions, including the selection of cultural traits that are included in the exchange and the final integration of cultural traits into the newly changed culture. Redfield, Linton, and Herskovits highlighted the need for precision in the description and analysis of the cultural elements exchanged among groups. They also argued that scholars needed to assess the nature of these cultural exchanges; whether the contacts were friendly or hostile, as well as the degree of coercion exercised by one group over another when pushing for cultural change. The authors fully recognized that conflict and hostility could characterize any cultural interchange, emphasizing the critical role of power dynamics in how the cultural exchange process worked. The time frames and sequences of cultural adoption delineated in the Memo are critical to understanding acculturation processes. The Memo also delineates a careful social analysis of the process of cultural sharing in terms of the effects of social status, gender, occupation and social position on who is most willing to accept new traits and who resists acculturative processes.

Redfield, Linton, and Herskovits defined three potential results of acculturation processes that were later echoed in the sociological and psychological literature, though with insufficient recognition of the contribution of anthropology. The first potential outcome of acculturation is acceptance. In acceptance, one group loses most of their cultural heritage and takes on the cultural traits from the donor group. The accepting group takes not only the cultural material and behaviors of the donor group, but their inner values as well. This process is what sociology came to focus on and labeled as assimilation. A second potential result of acculturation is adaptation, which involves combining new and original cultural features into a cultural whole resulting in a "historical mosaic" [1:148]. This mosaic can consist of integrated cultural features and practices or conflicting elements. Contemporary concepts for this process are hybridity or creolization, and have been the focus of later anthropological studies on cultural change. A third possible result of acculturation processes is reaction, in which counter-acculturative movements arise in response to cultural oppression or as an unforeseen negative result of the efforts to integrate cultural features from the groups holding very different cultural features. Reaction can result from a sense of pride in the older culture or as compensation for attitudes of discrimination by one culture towards the other. The Memo presages much of the debates in acculturation research for the next 80 years across anthropology, psychology and sociology. 


\section{Melville Herskovits: The Concepts of Real History and Hybridity}

"Historicity is an important tool, whose employment materially increases the deftness with which the analysis of the nature and functioning of culture can be accomplished." [11:8]

The next milestone in Anthropology's contribution to acculturation studies is found in Herskovits' $[11,14,15]$ work on Haiti's "voodoo" cult. In it, Herskovits continued the development of acculturation scholarship with an emphasis on "real history" and on advancing the concept of creolization as a final product of cultural exchange. Herskovits [15] developed a series of case studies that were an opportunity to illustrate the conceptual and methodological value of the Memo. Furthermore, in his work on acculturation, Herskovits saw an opportunity to criticize two pitfalls in the approaches to the study of culture that he saw among his colleagues at the time: their focus on documenting contained and pristine cultures, and their anti-historical perspective.

Herskovits' [14, 15] work on Haiti's "voodoo" cult saw it as a form of hybrid product in which elements of African and French cultures came together to form a new whole. Herskovits [15:65] argued that hybrid cultures are often the most common results of acculturation processes: "Perhaps this, to a far greater extent than is realized, is the result of most extended contacts between cultures, rather than the more conventionally accepted dictum that contact eventuates in the extinction of one by the other." Herskovits argued forcefully that to understand cultural hybridization it was critical first to understand the specific cultural elements that entered into contact prior to their mixture. Haiti's "voodoo" cult was not a product of some generalized African and French cultures, but rather of specific African cultures brought by African slaves and French colonists to Haiti. By contextualizing the cultural exchanges of slaves and colonists within specific historical processes, Herskovits framed them within what he called "real history."

Both Herskovits [11] and Hallowell [16] argued that a focus on de contextualized cultural traits in acculturation research was misguided. Herskovits argued that the goal of acculturation studies should be to view the analysis of cultural traits as just the beginning of the process and that the end goal was to integrate the analysis into a broader cultural and historical investigation to understand the emergence of new cultural wholes. Similarly Hallowell [16] argued against the "crude pigeonholing" of cultural traits in the analysis of acculturation processes. These critiques resonate with the present problematic use of scales of cultural traits in psychology as proxies for acculturation processes. One can only speculate about how much more useful immigration and acculturation studies could have been had these understandings of the dynamics of historical and cultural diversity been fully incorporated into later research.

\section{SSRC Summer Seminar on Acculturation}

"Acculturation is, however, neither a passive nor a colorless absorption. It is a culture-producing as well as culture-receiving process. Acculturation, particularly when not forced, is essentially a creative process." [2:985]

In 1953, almost two decades after the first Memo, four anthropologists (Homer Barnett, Bernard Siegel, Evon Vogt, and James Watson) and one sociologist (Leonard Broom) proposed an inter-university summer seminar to be funded by the Social Science Research Council. The participants spent two months reviewing the status of acculturation research. Their goal was equally to review the literature that had been published in the intervening period, as well as to update and advance the conceptualization of acculturation and to propose new research directions. Interestingly, their article started by commenting on how sociologists and psychologists had become interested in acculturation, perhaps forecasting the disciplines that would end up dominating acculturation research in the decades that followed. We highlight key ways in which their suggestions advanced the study of acculturation.

As the quote that opens this section indicates, the Summer Seminar came to see acculturation as a largely creative process resulting from the interchange of cultural systems under different conditions. The researchers were not naïve to the impacts of forced acculturation on minority groups; Bloom had studied the Japanese internments during World War II and Vogt had worked with Indigenous people in the Southwest and in Mexico. But they also saw the possibilities, following Herskovits, of new syncretic cultural forms emerging from acculturation processes.

The authors argued that change is a characteristic of all cultural systems, and has been throughout history. Acculturation, however, is a particular form of cultural change that takes place exclusively when groups with "autonomous cultural systems" meet [2:974]. The focus of acculturation research should then be on cultural systems, not on individuals, although they recognized that individuals undergo the changes. They posited that acculturation situations presented the best opportunities for understanding "cultural dynamics." To understand these dynamics of cultural change in acculturation, researchers were encouraged to include dimensions such as the demographic characteristics of cultural group members entering in contact that went beyond more typical cultural analyses. Their work was a critique of more static and de-contextualized views of culture in anthropology, and built on Herskovits' critique of the anti-historical stance of much of anthropology at the time. While their points may sound dated in anthropology today, their critique still resonates with the limited and cross-sectional way that acculturation has been studied in psychology and other fields. 
The authors posited that acculturation research would greatly benefit from understanding cultural groups' properties, and spent considerable effort discussing dimensions such openness to change; the flexibility or rigidity of their internal structures; and their capacity to adapt and diversify. The authors suggested that these properties are relevant to understanding how cultural systems react during inter-cultural encounters, and to explain potential problems arising from them. These types of analyses are all but lost in most current acculturation research.

The authors spent considerable time analyzing cultural "boundary-maintaining mechanisms," which presaged the work of Barth on Ethnic Groups and Boundaries [17]. The authors note that "...culture changes induced by contacts between ethnic enclaves and their encompassing societies would be definable as acculturation, whereas those resulting from interactions of factions, classes, occupational groups or other specialized categories within a single society would not be considered so" [2:974].

Their contrast of the anthropological study of acculturation and the sociological study of assimilation is worth reviewing in some detail as it provides important correctives to much contemporary research. They argued that for the assimilation of one group by another to occur two conditions were necessary. First, the assimilating group must learn the culture of the other group. Second, the other group must allow for the assimilating group to participate fully in society as they gain the appropriate cultural skills, thus developing an important political dimension to the research. They noted that complete assimilation was rare in actuality, though was often used in the sociological literature as the most common outcome: "Complete assimilation, like complete fusion, is much less frequent in fact than is indicated by the frequency with which the term is used" [2:988]. Despite these early insights, current acculturation research has for the most part focused on describing and assessing ideal types of acculturation outcomes among individuals, which often include assimilation, rather than detailing the actual lived experiences of acculturation [18].

The authors contrasted sociology's focus on immigrants to the U.S. as compared to anthropology's focus on nonimmigrant and non-Western peoples. They noted that up to the time of their article, most immigrants to the U.S. had been from Western Europe and that both immigrants and those in power in the U.S. shared a commitment to assimilation. Rather, they noted in the anthropological cases, the West had come as colonizers to the societies where anthropologists were conducting their research. Thus, there was much more tension between cultural groups and much less interest in assimilation among those who were being colonized. They also noted that controversies over how to analyze the experience of African Americans reflected these different perspectives and "... may account for an important part of the failure to make more of a joint and co-ordinate contribution to acculturation research" between anthropologists and sociologists [2:989]. These comments shed light on the current interdisciplinary tensions in acculturation research.

Their comments on the role played by language, while presented in the Appendix to the report, raised important issues for current acculturation research. While contemporary acculturation research, again particularly in psychology, treats language as a trait to be measured with a few Likert scale items, the authors argue that "language communication is a principal medium for the flow of cultural elements and provides an important clue for assessing the dynamics of this transfer" [2:994]. They highlight the development of multilingualism and also the development of creolized languages. They note that in studying acculturation it is critical to examine the social characteristics of those who become multilingual, of the situational nature of the use of one language over another, and the processes for developing skills in multiple languages.

\section{Melford Spiro and the Study of American Ethnic Groups}

"Anthropological studies of American ethnic groups,
although extremely limited, are sufficient to indicate
what a great loss to both culture theory and
acculturation theory our neglect of these groups have
been." [19:1248-1249]

In his 1955 article, Spiro made a compelling case for anthropology to take on the issue of the acculturation of U.S. ethnic groups, an issue that had been raised by the participants in the SSRC Summer Seminar [2]. Spiro saw the study of U.S. ethnic groups as a unique window into acculturation processes. He described the dearth of publications on the acculturation of these groups in the U.S., noting that until 1955 there were approximately 30 anthropological papers on this topic. The lack of attention to U.S. ethnic groups extended to the major texts on acculturation of the time $[15,20]$. Furthermore, he noted that this field was already dominated by sociology and psychology.

Spiro questioned why anthropologists had focused so extensively on the study of acculturation in the context of colonialism when the phenomenon was happening closer to home, among immigrant groups living primarily in U.S. cities. He observed that under colonial conditions, acculturation processes involve a numerically smaller, but politically more dominant group imposing its culture on the local group and threatening that group's integrity. In contrast, in the U.S., the cultures that immigrants bring with them are threatened by a larger and politically more dominant group. Spiro saw in these two different situations an opportunity for developing comparative acculturation research. The connection between early acculturation studies and colonialism, however, is one of the reasons why contemporary anthropologists find this field so problematic. As with the work of the authors previously reviewed here, Spiro's insights went mostly unheeded in the subsequent 60 years. 
Spiro went on to summarize what had been learned from the few acculturation studies conducted in the U.S., mostly by sociologists and by some anthropologists. Strikingly the largest number of studies had been done on Mexicans and other Latinos (9) much as is found today, followed by Jews (6), Japanese (5) and Italians (4). He started by reviewing what in many ways were the complementary processes of social mobility and nativism. He noted that social mobility “... is a threat to both the group's social solidarity and to its cultural survival" and that social success may be viewed as a betrayal of the ethnic group [19:1243]. Nativism was expressed through various forms of prejudice and discrimination by the larger society and served to block the social mobility aspirations of immigrant individuals and groups. In response, ethnic identification and pride served as buffers against these forms of prejudice.

Spiro also noted that family, food choices, and religion often change at a slower pace than other aspects of culture, and that they served as additional buffers against discrimination from the larger society. In the acculturation process undergone within families, parents were the agents of cultural continuity, while children became the agents of change. He pointed out that this may happen because children acculturate faster than adults, which results in inter-generational tensions that pose threats to the family unity. The mostly negative impact of acculturation on family dynamics and cohesiveness became an important area of research among developmental psychologists interested in immigrant youth.

Spiro's observations on the multiple roles that religion played in acculturation processes are particularly relevant to today's discussions about minority religious groups and the place of religious minorities in Western societies. He suggested that religious institutions may buffer immigrants against the pressures from the larger society and religious change may signal broader processes of social mobility and assimilation. The studies cited by Spiro were conducted with Jews, but there is certainly a need to expand these to other religious groups in diverse contexts. Although small, this group of studies of U.S. ethnic groups provided different windows into acculturation processes than the bulk of previous anthropological work on acculturation.

\section{Beal's Review of the State of Acculturation Research}

“... A re-examination of the subject [that is, acculturation] is in order, particularly with respect to the reciprocal aspects of acculturation, its relation to the problem of assimilation, and the propriety of extending the term to studies of contact between groups within a culture and to studies of migrant groups." [21:383].

Just a few years after Spiro's [19] article, Beals [21] reviewed the literature on acculturation again and challenged the prejudice against acculturation studies among American anthropologists. He noted that Leslie Spier, who was the Editor of the American Anthropologist when the Memo was published, raised the question of whether acculturation studies should even be published in the flagship journal. When he addressed the Annual Meeting, Spier argued that acculturation studies belonged in sociology not anthropology journals, and put forth a motion not to publish acculturation papers in $A A$. While the motion was quickly tabled, Spier's narrow understanding and negative perception of acculturation studies is still very much alive within anthropology today.

We highlight the core ideas about acculturation that Beals summarizes in his chapter in Tax's influential collection Anthropology Today [21]. Beals carefully reviewed a number of studies of acculturation in American and British anthropology to make his points. He organized his critique in two areas: the conceptualization and definition of acculturation and the methodological issues of its study. One key feature of U.S. studies of acculturation is the use of the concept of force as distinguishing between studies of acculturation and diffusion. Acculturation processes often involved one group forcing the other to change its culture. While that force could be overt, force could also be indirect through psychological and other means. Diffusion, on the other hand, does not involve the use of force.

Beals made the important point that acculturation has always been a dynamic process in anthropology that provides an opportunity to compare processes of change. His perspective certainly contrasts with the more cross-sectional approaches to acculturation assessment in psychology, and of assimilation studies dominant in the sociological literature. Beals noted that a wholly acculturated individual is somewhat of an oxymoron as once someone is fully assimilated, the process of acculturation would have ceased. Furthermore, Beals pointed out the confusion in the field with the unit of analysis. Studies talk about "acculturated individuals," however, acculturation refers to a group level phenomenon.

Beals highlighted the role of historical dimensions to acculturation studies. He particularly analyzed the work of Herskovits [14] on African cultures in the New World and of Tax [20] on the impact of Spanish colonization in Latin America. Both series of studies emphasized the syncretic nature of acculturation situations that produced new cultures. The author, however, realized the need to extend acculturation studies beyond the research of situations of contact between Europeans and Native populations. He suggested incorporating the analysis of contact between sub-groups within a larger culture, as well as the study of migrant groups.

Beals also highlighted linguistic studies of acculturation as an important new dimension of understanding acculturation processes. He suggested that linguistic measures could be used to develop indices of acculturation; a comment that presaged the centrality of language items in 
current acculturation scales. What is different in Beals' suggestion is not just the use of simple, cross-sectional indicators of language use, but a more sophisticated, processual understanding of the linguistic dimensions of acculturation. In 1962, Beals [21] saw linguistics as a potentially important dimension that was still underdeveloped and underexplored.

Beals concluded his review with the following assessment that resonates today: "Such a review as the present suggests strongly the need for serious stocktaking and reformulation of the field of acculturation. There is an urgent necessity to re-examine our conceptual apparatus and to reach agreement on objectives and methods which will produce more comparability in studies and which will develop a series of really significant hypotheses" [21:392]. He listed several steps that would inform the research program on acculturation going forward. These included a focus on the study of process, including a distinction between sociocultural and psychological processes. He argued that to study dynamic processes, a time dimension is critical and that acculturation studies should be longitudinal. Beals argued that quantification of acculturation assessments were central to allowing for the comparability of studies across settings, but that quantification was not a goal itself.

\section{Revisiting the Concepts of Acculturation and Assimilation}

"Rather than a unidirectional perspective, the literature reveals consistent justification for viewing acculturation as a two-way, or reciprocal, process." [22:354]

In 1974, the sociologists Teske and Nelson [22] provided a very useful summary and comparison of the differences between acculturation and assimilation in their article for the American Ethnologist, interestingly an anthropological rather than a sociological journal. Their clarifications of these distinctions, built on a review of 40 years of research, provided important contrasts between these two concepts. Although 40 years have passed since their review, we find many points worth re-emphasizing as we make the case for revitalizing anthropology's engagement with acculturation research.

As with Beals and writers before them, Teske and Nelson argued that acculturation is a "dynamic process," rather than a single event [22]. Because of its processual nature, acculturation needs to be studied with dynamic methodologies. They also highlighted that acculturation is a group rather than individual process, and while individuals must acculturate, the process is initiated by the encounter between cultural groups. The authors addressed the unidirectional - bidirectional discussion by stating that acculturation is almost always a two-way process [22:354]. The simplicity and clarity of their insights should have solved the debates in the field long ago. They also highlighted the issue of the roles of power and dominance in acculturation processes. Dominance can occur through political processes of the application of power and/or through normative processes where one group is viewed as superior to the other by one or both of the groups.

As sociologists, the authors were in a privileged position to clarify the distinctions between acculturation and assimilation. They posited these as separate processes, even though the terms have continued to be used interchangeably in the literature, including within anthropological studies. They suggest that assimilation always requires the incorporation of one group into another; while acculturation has many potential outcomes in the relationships between groups in cultural contact. Thus, assimilation is a unilineal process that occurs in the direction of the dominant group. Furthermore, for assimilation to occur, the dominant group has to accept the new group; while acculturation can occur without acceptance into the broader society. Assimilation can take place both as individual and group process. These clarifications [see Table 1 for a summary of the key differences between acculturation and assimilation] bring us to the point of assessing the current state of acculturation research and where a re-engagement by anthropology can provide important correctives and new directions to the study of acculturation. 
Table 1. Acculturation and Assimilation

\begin{tabular}{|c|c|}
\hline Acculturation & Assimilation \\
\hline \multicolumn{2}{|c|}{ Acculturation and Assimilation are separate, distinct processes [22:365] } \\
\hline $\begin{array}{l}\text { Acculturation is a multidirectional process of cultural change that results } \\
\text { from continuous first-hand contact between groups from different } \\
\text { cultural backgrounds. }[1,22]\end{array}$ & $\begin{array}{l}\text { Assimilation is a unidirectional process of cultural change in which one } \\
\text { cultural group adopts cultural features of a dominant group and loses } \\
\text { most of its cultural heritage. }[1,2,22]\end{array}$ \\
\hline $\begin{array}{l}\text { Acculturation can lead to three potential outcomes: acceptance (known } \\
\text { in sociology as assimilation); adaptation (also known as hybridity or } \\
\text { creolization); and reaction (contra-acculturation movements arise). [1] }\end{array}$ & $\begin{array}{l}\text { Assimilation is a potential outcome of the acculturation process when } \\
\text { the dominant group forces cultural traits on the assimilating group [15] }\end{array}$ \\
\hline $\begin{array}{l}\text { Acculturation can occur without acceptance of one cultural group into } \\
\text { the broader society. [22] }\end{array}$ & $\begin{array}{l}\text { For assimilation to occur, the dominant group has to accept the } \\
\text { assimilating group. The "reward" of assimilation is the opportunity to } \\
\text { fully participate in the dominant society once the appropriate cultural } \\
\text { skills are learned. [22] }\end{array}$ \\
\hline $\begin{array}{l}\text { Acculturation involves cultural interchange among groups, thus it is } \\
\text { important to understand which cultural traits are exchanged, as well as to } \\
\text { assess the nature of these cultural exchanges. }[1,2,15]\end{array}$ & $\begin{array}{l}\text { The assimilating group must learn the culture of the other group. The } \\
\text { accepting group takes not only the cultural, material, and behaviors of } \\
\text { the donor group, but their inner values as well. }[15,22]\end{array}$ \\
\hline $\begin{array}{l}\text { Acculturation refers to a group level phenomenon. The unit of analysis } \\
\text { in acculturation studies is cultural systems, not individuals. }[1,2,22]\end{array}$ & Assimilation refers both to individual and group processes. $[1,22]$ \\
\hline
\end{tabular}

\section{Current Re-assessments of Acculturation}

"Anthropologists do not speak much these days of 'acculturation."'[4:173]

“... the main theoretical concerns remain the same: is there culture in cross-cultural research?"[23:88]

It is timely for anthropology to reassert its critical role in defining, conceptualizing and investigating the complex and dynamic processes of acculturation. Within sociology and psychology, there have been major reassessments of the field of acculturation research [18, 23-26]. Often these reviews and critiques point us back to what we have been referring to as the "anthropological program on acculturation." It is stunning to read the internal critiques of these other fields by experts within them. Their prescriptions for new directions and approaches contain ideas that anthropologists have been proposing for decades. In this section, we briefly summarize these critical assessments as a springboard for how anthropology can lead a revitalized approach to acculturation research.

Chirkov edited a special issue of the International Journal of Intercultural Relations [23] to develop a "Critical Acculturation Psychology." Each of the authors in this special issue provided a critique of past research and examples of alternative approaches to studying acculturation. Rudmin [27], who had already made several important interventions in this area, continued presenting historical bibliographies of acculturation usage and developing a devastating critique of psychologists' conceptual and methodological approaches [18]. As Chirkov summarized previous critiques, he faulted previous work in psychology as (a) being overly concerned with finding universal processes; (b) using simple quantitative measures that do not accurately assess acculturation and assure the uniformity of findings; (c) misunderstanding the centrality of language to culture; and (d) relying on cross-sectional studies using quantification and statistics that cannot possibly assess the diversity and complexity of acculturation processes. $\mathrm{He}$ argued that psychological research on acculturation is both ahistorical and acultural; features which are the antithesis to the framings of acculturation research within anthropology. Waldram [4] concludes in his anthropological commentary on this special issue by calling for a renewed dialogue between psychology and anthropology, a call echoed in this paper as well.

Simultaneously, sociology has revisited its core concept of assimilation in a critical way that also brings its research program closer to anthropology. Glazer in 1993 asked the question "Is Assimilation Dead?" and answered in the following way: "The word may be dead, the concept may be disreputable, but the reality continues to flourish" [24:134]. We would argue that it is good that the unilineal process of homogenization implied in assimilation is dead and that the process of acculturation remains as a more robust concept. In his paper on the "The Return of Assimilation?" Brubaker [25] compares perspectives on immigration in France, Germany and the United States. He argues against the return of the "old assimilation" with its assumptions about homogenization and conformity to some imagined and often imposed national culture. He explains that his changing understanding has "... entailed a shift from an assimilationist understanding of assimilation - a global empirical expectation and normative endorsement of assimilation - to an agnostic stance, varying by domain and reference population, concerning both the likelihood and the desirability of assimilation" [25:544]. Several sociologists have provided a very different and more contextualized direction for the study of immigrants in the U.S. in a series of studies of second-generation youth in secondary schools [see 28-30 among others]. These studies, using qualitative and quantitative methods and being explicitly comparative across ethnic groups, have provided richer multidimensional understandings of the processes of immigrant incorporation than imagined in Brubaker's formulation.

These critiques bring us back to the anthropological approach to acculturation research in all its dynamic complexity, historical specificity, and contextual 
frameworks including the impacts of differential power dimensions on acculturation processes. In the next section, we propose a renewed anthropological agenda on acculturation that builds on anthropology's intellectual history and methodological approaches that responds to the needs of acculturation research within the contemporary processes of globalization.

\section{A Revitalized Anthropological Approach to Acculturation}

"Scales, surveys or predictions cannot capture the dynamism of the constituents of meaning." [31:464]

The outlines of a revitalized anthropological approach to acculturation should be fairly clear by this point in the paper. First, the understanding of acculturation should be multidimensional in examining the complex ways that individuals and groups encounter new cultural contexts and respond to the pressures to adopting new languages and other cultural features. Research should also be attuned to the emergence of syncretic cultural practices. Second, studies should focus on how acculturation unfolds over time, as this process clearly does not follow a unidirectional path, but proceeds along circuitous routes. Furthermore, different dimensions of cultural practice may move in different time frames and may reactivate under special circumstances. Third, research should be attuned to the power dynamics of acculturative processes. Great emphasis should be placed on capturing the roles of stigmatization and discrimination in shaping acculturation processes, as well as of state and local institutions in pressuring or aiding individuals and groups to change. At the same time, attention should be paid to the agency of individuals and groups to resist and push back on these pressures. Responses may include intensifying some cultural practices and developing new institutional forms to resist these pressures.

In order to develop a revitalized anthropological approach to acculturation, we propose an expansive definition based on the above propositions. Acculturation is a complex process in a multicultural context that comprises both enculturation and assimilation. Acculturation is the broadest process that can take multiple forms and directions depending on the changing social contexts of different cultural groups in contact. Acculturation involves a range of forms of cultural learning and practice. By enculturation, we mean the processes that individuals, families and communities go through to learn and maintain their own culture or cultures. Assimilation refers to the processes of adopting cultural features from a new contact population, often a population that is socially and politically dominant. Assimilation can occur to the broader population or to subgroups of the population; what Portes and Rumbaut [28] term "segmented assimilation." What is consequential in the processes of acculturation are not the specific traits or elements, but the rules and processes that define acculturation.

Acculturation scales should be altogether abandoned, as clearly no single scale can capture these processes. In much of current acculturation research there has grown to be a tyranny of acculturation scales that make false promises about taking account of participants' "culture" in the research. This approach is counter-productive for moving acculturation research forward.

Acculturation research must incorporate contextual and historical dimensions, as separating its study from social, political and economic dynamics does not make sense. This is because acculturation always occurs in a broader social, ecological, and economic context and is strongly shaped by these dimensions. At the same time, the historical dimensions of acculturation processes must be integrated into research, as the specificities are essential to understanding acculturation processes.

Acculturation research should embrace comparative studies, especially in situations when multiple groups are entering the same social context and responding in diverse ways. This approach is particularly needed as globalization often results in the convergence of several cultures. Focusing on only one group at a time misses many key dimensions of acculturation processes. At the same time, seeing only universal acculturation processes is reductionist, counterproductive, and misguided.

Methodologically, acculturation studies need to incorporate qualitative and quantitative methods to capture the dynamism of acculturation. Research methods that allow us to understand acculturation processes from the perspective of those going through it is critical. This argues for an expansion of research on U.S. immigrant groups, as argued by Spiro [19], and on immigrants in other countries as well. A promising direction is phenomenological studies of acculturation to detail the lived experiences of immigrants $[21,32]$.

In our study of diverse immigrant college students using focus groups [33], we identified several important dimensions of acculturation related to language use that are missing in current acculturation scales. For instance, a key dimension to understanding language use among immigrant participants were the family rules about language use in the home. These rules mattered greatly to the development of bilingualism, as families adopted conscious strategies to both promote family language maintenance and encourage learning English. Participants in the study were also acutely aware of the politics of language use, which had both historical and current dimensions depending on the students' affiliations with different countries and cultural groups. In some communities, ethnic schools created by families and churches, provided not only reinforcement of their language and cultural practices, but also acted as buffers against broader societal discrimination against immigrants. In line with anthropological approaches, these few examples suggest the kinds of insights that can be gained by engaging with people experiencing acculturation directly and interviewing them in ways which allow them to reflect on the 
multiple dynamics of acculturation processes. Other similar approaches can be found in the work of sociologists Portes and Rumbaut [28] and Kasinitz and colleagues [29, 30]. These authors demonstrate the value of combining in-depth interviews with broader surveys of acculturation experiences in longitudinal studies.

The ultimate question becomes why revitalize the acculturation construct and why anthropology in particular should lead the way in this new program of research? Globalization processes have resulted in unprecedented movements of people and led to intense interactions of diverse peoples from around the world. Acculturation is one of many concepts that focuses our attention on investigating the complex and multifaceted ways that these encounters are occurring and on the processes of how societies continue to evolve. Anthropology has a long and rich history that we hope this paper has conveyed effectively. The urgency of the current world situation calls for a revitalized effort to think deeply about acculturation processes through the lens of our history and the creativity of our future.

\section{Acknowledgements}

Dr. Guarnaccia was supported by Award Number R21HD065053 from the Eunice Kennedy Shriver National Institute of Child Health and Human Development for the research and writing of this paper. The content is solely the responsibility of the authors and does not necessarily represent the official views of the Eunice Kennedy Shriver National Institute of Child Health and Human Development or the National Institutes of Health. Dr. Hausmann-Stabile was supported by a postdoctoral fellowship from the National Institute of Mental Health [T32 MH19960].The authors wish to thank Ms. Cortney Bruno for her editorial assistance.

\section{REFERENCES}

[1] R. Redfield, R. Linton, M. J. Herskovits. Memorandum for the Study of Acculturation, American Anthropologist, Vol.38, No.1, 149-152, 1936.

[2] Social Science Research Council Summer Seminar on Acculturation. Acculturation: An Exploratory Formulation, American Anthropologist, Vol. 56, 973-1000, 1954.

[3] P. Greenfield. What Psychology Can Do For Anthropology, or Why Anthropology Took Postmodernism on the Chin, American Anthropologist, Vol.102, No.3, 564-576, 2000.

[4] J. B. Waldram. Is There a Future for "Culture" in Acculturation Research? An Anthropologist's Perspective, International Journal of Intercultural Relations, Vol.33, No.2, 173-176, 2009.

[5] N Glick Schiller, L. Basch, C. Szanton Blanc. From Immigrant to Transmigrant: Theorizing Transnational Migration, Anthropological Quarterly, Vol.68, 48-63, 1995.
[6] L. Lamphere. Migration, Assimilation and the Cultural Construction of Identity: Navajo Perspectives, Ethnic and Racial Studies, Vol.30, No.6, 1132-1151, 2007.

[7] D. Glazer and D. P. Moynihan. Beyond the Melting Pot, MIT Press, Cambridge, 1970 (1963).

[8] J. W. Berry. Integration, Acculturation and Adaptation, Applied Psychology: An International Review, Vol.46, 5-34, 1997.

[9] L. M. Hunt, S. Schneider, B. Comer. Should "Acculturation" Be a Variable in Health Research? A Critical Review of Research on US Hispanics. Social Science \& Medicine, Vol.59, No.5, 973-986, 2004.

[10] M. J. Herskovits. The Significance of the Study of Acculturation for Anthropology, American Anthropologist, Vol.39, No.2, 259-264, 1937.

[11] M. J. Herskovits. Some Comments on the Study of Cultural Contact, American Anthropologist, Vol.43, No.1, 1-10, 1941.

[12] A. E. Becker. Body, Self, Society: The View from Fiji, University of Pennsylvania Press, Philadelphia, 1995.

[13] J. W. Berry, U. Kim, S. Power, M. Young, M. Bujaki. Acculturation Attitudes in Plural Societies, Applied Psychology, Vol.38, No.2, 185-206, 1989.

[14] M. J. Herskovits. African Gods and Catholic Saints in New World Negro Belief, American Anthropologist, Vol.39, No.4, 635-643, 1937.

[15] M. J. Herskovits. Acculturation: The Study of Culture Contact, Peter Smith, Gloucester, 1958 (1938).

[16] A. I. Hallowell. Review of Acculturation: the Study of Culture Contact by Melville J. Herskovits, American Anthropologist, Vol.42, 690-692, 1940.

[17] F. Barth, Ed. Ethnic Groups and Boundaries: The Social Organization of Culture Difference, Little, Brown, Boston, 1969.

[18] F. W. Rudmin. Constructs, Measurements and Models of Acculturation and Acculturative Stress, International Journal of Intercultural Relations, Vol.33, No.2, 106-123, 2009.

[19] M. E. Spiro. The Acculturation of American Ethnic Groups, American Anthropologist, Vol.57, No.6, 1240-1252, 1955.

[20] S. Tax. Selective Culture Change, The American Economic Review, 315-320, 1951.

[21] R. Beals. Acculturation. In Anthropology Today: Selections. Sol Tax, ed., 375-395, University of Chicago Press, Chicago, 1962.

[22] R. H. C. Teske, B. H. Nelson. Acculturation and Assimilation: A Clarification. American Ethnologist, Vol.1, 351-367, 1974.

[23] V. Chirkov. Critical Psychology of Acculturation: What Do We Study and How Do We Study It, When We Investigate Acculturation? International Journal of Intercultural Relations, Vol.33, No.2, 94-105, 2009.

[24] N. Glazer. Is Assimilation Dead? The Annals of the American Academy of Political and Social Science, Vol.530, No.1, 122-136, 1993. 
[25] R. Brubaker. The Return of Assimilation? Changing Perspectives on Immigration and its Sequels in France, Germany, and the United States, Ethnic and Racial Studies, Vol.24, No.4, 531-548, 2001.

[26] F. W. Rudmin. Critical History of the Acculturation Psychology of Assimilation, Separation, Integration, and Marginalization, Review of General Psychology, Vol.7, No.1, 3-37, 2003.

[27] F. W. Rudmin. Field Notes from the Quest for the First Use of 'Acculturation,' Cross-Cultural Psychology Bulletin, Vol.37, 24-31, 2003.

[28] A. Portes, R. G. Rumbaut. Legacies: The Story of the Immigrant Second Generation, University of California Press, Berkeley, 2001

[29] P. Kasinitz, J. H. Mollenkopf, and M. C. Waters, eds. Becoming New Yorkers: Ethnographies of the New Second
Generation, Russell Sage Foundation, New York, 2004.

[30] P. Kasinitz, J. H. Mollenkopf, and M. C. Waters, eds. Inheriting the City: The Children of Immigrants Come of Age, Russell Sage Foundation \& Harvard University Press, New York \& Cambridge, 2009.

[31] J. Skuza. Humanizing the Understanding of the Acculturation Experience with Phenomenology, Human Studies, Vol.30, 447-465, 2007.

[32] P. R. Smokowski, M. Bacallao. Becoming Bicultural: Risk, Resilience, and Latino Youth, New York University Press, New York, 2011.

[33] P. Guarnaccia, M. Gilberti, C. Hausmann-Stabile, I. Martinez. Immigrant Students' Journeys to Higher Education: What Makes the Process of Acculturation Successful? Institute for Health, Health Care Policy and Aging Research, Rutgers University, 2013.

[http://www.ihhcpar.rutgers.edu/org_units/default.asp?v=2\& $\mathrm{o}=32]$ 